\title{
Clinical significance of coexisting histological diffuse type in stage II/III gastric cancer
}

\author{
HIROAKI TANAKA $^{1}$, MAMI YOSHII ${ }^{1}$, TAKUMI IMAI ${ }^{2}$, TATSURO TAMURA ${ }^{1}$, TAKAHIRO TOYOKAWA ${ }^{1}$, \\ KAZUYA MUGURUMA $^{1}$, KOSEI HIRAKAWA ${ }^{1}$ and MASAICHI OHIRA ${ }^{1}$ \\ Departments of ${ }^{1}$ Gastroenterological Surgery and ${ }^{2}$ Medical Statistics, \\ Osaka City University Graduate School of Medicine, Osaka 545-8585, Japan
}

Received July 22, 2020; Accepted August 24, 2021

DOI: $10.3892 / \mathrm{mco} .2021 .2397$

\begin{abstract}
Since 1965, the Laurén classification has been used most commonly for gastric adenocarcinoma, with two main types: intestinal type and diffuse type. Signet ring cell carcinoma (Sig) and non-solid poorly differentiated adenocarcinoma (Por2) are the histological forms of diffuse type that are often found in advanced tumors, and they seem to be associated with a poor prognosis. S-1-based adjuvant chemotherapy for patients with stage II/III gastric cancer has generally been accepted in Japan, but histological type does not alter treatment strategy. The aim of the present study was to investigate the prognostic impact of the histopathological mixture of Sig and Por2 in patients with stage II/III gastric cancer treated with S-1 adjuvant chemotherapy. The clinicopathological data of 968 patients with gastric carcinoma who underwent gastrectomy between 2007 and 2016 at Osaka City University Hospital were retrospectively analyzed. In the present study, tumors containing Sig or Por2 were classified as diffuse type, and those not containing them were classified as intestinal type. There were 307 cases of diffuse type and 661 cases of intestinal type. Diffuse type included 189 cases with Sig. A pathological diagnosis of Sig was an independent risk factor for peritoneal recurrence in patients with stage II/III gastric cancer. Patients with diffuse type had a worse overall survival rate than those with intestinal type at stage III gastric cancer. Among the patients who received S-1 adjuvant chemotherapy, the prognosis of patients with stage III gastric cancer with Sig but not Por2 was significantly worse compared with that of patients with intestinal type. Therefore, the present study revealed that the coexistence of Sig in the primary tumor was associated with a poor prognosis in patients with stage III gastric cancer. The current findings suggested that,
\end{abstract}

Correspondence to: Dr Hiroaki Tanaka, Department of Gastroenterological Surgery, Osaka City University Graduate School of Medicine, 1-4-Asahimachi, Abeno, Osaka 545-8585, Japan E-mail: hiroakitan@med.osaka-cu.ac.jp

Key words: gastric cancer, signet ring cell carcinoma, diffuse type, prognosis since mixed Sig gastric cancer had a high risk of peritoneal recurrence even if adjuvant chemotherapy was performed, the pathological diagnosis should be considered when determining the therapeutic strategy for adjuvant chemotherapy in patients with stage III gastric cancer.

\section{Introduction}

Gastric cancer is a highly heterogeneous disease. According to Laurén's classification, gastric cancer is categorized as intestinal type and diffuse type (1). Intestinal tumor cells exhibit adhesion and have tubular formation. On the other hand, diffuse type exhibits single cells or poorly cohesive cells infiltrating the gastric wall, such as signet ring cell carcinoma (Sig) and non-solid poorly differentiated adenocarcinoma (Por2) according to the Japanese Classification, and they are included in the poorly cohesive carcinoma subtype in the World Health Organization (WHO) classification of $2010(2,3)$. Sig and Por2 tumors tend to infiltrate diffusely and preferentially develop peritoneal metastases, resulting poor clinical outcomes (4). Gastric carcinomas often consist of a mixture of histological patterns (5). The percentage of mixed tissue is reported to be $21 \%$ (5). In the Japanese Classification of Gastric Cancer, the predominant histologic type is used even if mixed with undifferentiated components, so it may be defined as differentiated type (2). Sig and Por2 often coexist with other histologies, but their clinical significance is unclear. Furthermore, the clinical difference between Sig and Por2 in advanced gastric cancer remains unclear.

Patients show various sensitivities to chemotherapy; therefore, tailoring anti-cancer drugs on an individual basis for the treatment of gastric cancer is important. S-1-based chemotherapy is a standard postoperative adjuvant therapy for patients with stage II or III gastric cancer in Asia (6). S-1, an oral fluoropyrimidine derivative, is known to be a pivotal agent for the treatment of patients with gastric cancer in Japan. The usefulness of S-1 alone or S-1 combined with cisplatin or docetaxel has been reported for peritoneal metastasis (7). Currently, the management of patients with gastric cancer is dependent on the clinical and pathological TNM stage. As a consequence, treatment guidelines have not yet been tailored by histology. Histological type could be a surrogate marker of disease biology. 
The aim of this study was to retrospectively investigate the relationship of the presence of diffuse type in primary tumor and clinicopathological background with prognosis, including recurrence after postoperative adjuvant chemotherapy, in patients with advanced stage II and III gastric cancer.

\section{Patients and methods}

Clinical data. A retrospective analysis of the gastric cancer database of the Department of Surgical Oncology, Osaka City University Graduate School of Medicine, was performed. Clinicopathological data of 968 patients with gastric carcinoma who underwent curative resection (i.e., R0 resection) without preoperative chemotherapy between 2007 and 2016 were examined. Patients with postoperative death within 30 days or incomplete follow-up were excluded.

The histological type was determined basically according to the 15th edition of the Japanese Gastric Cancer classification. According to it, the tissue-type is decided based on the quantitatively predominant tissue-type. In this study, intestinal predominant type was defined as the histological type in which papillary adenocarcinoma (pap), well-differentiated tubular adenocarcinoma (tub1), moderately differentiated adenocarcinoma (tub2), or solid-type poorly differentiated adenocarcinoma (por1) was quantitatively dominant, and diffuse predominant type was defined as the histological type in which Por2 and Sig were dominant. Furthermore, diffuse mixed intestinal type was defined as present when Por2 or Sig were mixed, even though the intestinal type was dominant. In this study, the intestinal type refers to a tumor that does not contain Sig or Por2 at all, and the diffuse type refers to both diffuse predominant and diffuse mixed intestinal types.

Adjuvant chemotherapy consisting of S-1 was basically administered orally twice daily for the first 4 weeks of a 6-week cycle. The dose of S-1 administered per day was based on the patient's body surface area as follows: $<1.25 \mathrm{~m}^{2}, 80 \mathrm{mg}$; $1.25-1.50 \mathrm{~m}^{2}, 100 \mathrm{mg}$; and $>1.5 \mathrm{~m}^{2}, 120 \mathrm{mg}$. Treatment of both groups was continued until one of the following occurred: disease progression, administration difficulty due to adverse effects, or decision to stop treatment at the discretion of the treating physician.

Statistical analysis. Kruskal-Wallis test with Bonferroni post hoc test, chi-square test and Fisher's exact test were used to assess the associations between histological types and clinicopathological features using SPSS ver.26 software (SPSS Japan). Overall survival (OS) and disease-free survival (DFS) curves were drawn using the Kaplan-Meier method. The day of surgery was used as the starting point for the measurement of OS. The log-rank test and Renyi test were used to assess the significance of differences in survival. Prognostic factors were analyzed using the cox proportional hazards model using the JMP software program (SAS Institute, Inc.). Renyi test was performed using $\mathrm{R}$ version 3.6.3 ( $\mathrm{R}$ Core Team, 2020). $\mathrm{P}<0.05$ was considered to indicate a statistically significant difference.

\section{Results}

Differences in background characteristics between diffuse type and intestinal type. The cohort in this study consisted of $218(22 \%)$ diffuse predominant type and 750 (78\%) intestinal predominant type cases. Overall, 89 of 750 intestinal predominant type had mixed diffuse type histology, which was defined as a diffuse mixed intestinal type (Table I). Finally, 661 cases of intestinal type and 307 cases of diffuse type were compared and examined (Table I). Diffuse type was more common in young women and type 4 gastric cancer than intestinal type, while early gastric cancer was abundant in the diffuse type, and $64 \%$ had pathological stage I. Patients with diffuse type had peritoneal recurrence more frequently than patients with intestinal type, whereas intestinal type had more hepatic recurrence caused by venous infiltration than diffuse type. A similar tendency was recognized in the comparison of diffuse mixed intestinal type and diffuse predominant type (Table I). In other words, diffuse mixed-intestinal type should be treated as diffuse type.

Clinical relevance of Sig compared to Por2. Table II shows a comparison of the background characteristics between Sig and Por2 in the diffuse type. Of the 307 patients with diffuse type, Sig was present in 189, Por2 in 177, and both Sig and Por2 in 59. Patients with Sig predominance without Por2 had more early cancers, less lymphatic invasion, and less recurrence, whereas Por 2 cases had more cases of pT3 or more, positive for lymph node metastasis, and pathological stage II/III than Sig cases. The background of the cases including both of Sig and Por2 was similar to that of Por2 cases, and peritoneal recurrence occurred at a high rate.

Of the 189 cases of Sig, 79 were cases in which Sig was histologically dominant, and 110 cases in which it was histologically non-predominant (Table III). A total of 139 (78\%) had histological predominance of Por2. There was no clinically significant difference between Por2-dominant and Por2-non predominant type. Sig-dominant tumors were more frequent in early-stage cancers, and peritoneal dissemination was more frequent in patients with Sig-non predominant cancers.

Peritoneal metastasis has a large effect on the prognosis, which accounts for most recurrences in the diffuse type. Therefore, factors associated with peritoneal recurrence were investigated using a Cox proportional hazards model (Table IV). On multivariate analysis using factors found to be related on univariate analysis, total gastrectomy and coexistence of Sig were independent risk factors associated with peritoneal metastases after curative surgery.

Impact of Sig on OS and relapse-free survival after $S-1$ adjuvant chemotherapy. The median length of follow-up was 36 months. Kaplan-Meier curves according to pathological stage are shown in Fig. 1. OS analysis by pathological stage showed that there was no difference between diffuse type and intestinal type in stage II (Fig. 1A). However, patients with diffuse type had a significantly worse prognosis in pathological stage III (5-year OS 42\%) compared to intestinal type (5-year OS 59\%) (Fig. 1B). Recurrence for peritoneal dissemination was seen in $14(24 \%)$ of 24 mixed Sig patients and $16(36 \%)$ of 45 mixed Por 2 patients. The difference in prognosis between patients with Sig and Por2 and those with both is shown in Fig. 1C. 5-year survival for patients with Sig alone was slightly better $(79 \%)$, but not statistically significant. 
Table I. Difference in clinicopathological characteristics between diffuse type $(n=307)$ and intestinal predominant type $(n=750)$.

\begin{tabular}{|c|c|c|c|c|c|}
\hline Characteristics & $\begin{array}{l}\text { Intestinal type } \\
\qquad(\mathrm{n}=661)\end{array}$ & $\begin{array}{l}\text { Diffuse mixed } \\
\text { intestinal type } \\
\qquad(\mathrm{n}=89)\end{array}$ & $\begin{array}{l}\text { Diffuse predominant } \\
\text { type }(n=218)\end{array}$ & $\begin{array}{l}\text { P-value (intestinal } \\
\text { vs. diffuse mixed and } \\
\text { predominant) }\end{array}$ & $\begin{array}{c}\text { P-value } \\
\text { (Diffuse mixed } \\
\text { vs. predominant) }\end{array}$ \\
\hline Median age, years & 70 & 65 & 64 & $0.003^{\mathrm{a}}$ & $0.632^{\mathrm{a}}$ \\
\hline \multicolumn{6}{|l|}{ Sex, n } \\
\hline Male & 175 & 57 & 121 & $<0.001^{\mathrm{b}}$ & $0.661^{\mathrm{b}}$ \\
\hline Female & 486 & 32 & 97 & & \\
\hline \multicolumn{6}{|l|}{ Macroscopic type, $\mathrm{n}$} \\
\hline Type 0 & 357 & 48 & 112 & $<0.001^{\mathrm{c}}$ & $0.113^{\mathrm{c}}$ \\
\hline Type 1,2,3 & 296 & 38 & 87 & & \\
\hline Type 4 & 8 & 3 & 19 & & \\
\hline \multicolumn{6}{|l|}{ Surgery, n } \\
\hline Distal gastrectomy & 471 & 70 & 158 & $0.210^{c}$ & $0.397^{\mathrm{c}}$ \\
\hline Proximal gastrectomy & 10 & 0 & 1 & & \\
\hline Total gastrectomy & 180 & 19 & 59 & & \\
\hline \multicolumn{6}{|l|}{$\mathrm{pT}, \mathrm{n}$} \\
\hline $1 / 2$ & 476 & 54 & 107 & $<0.001^{\mathrm{b}}$ & $0.049^{\mathrm{b}}$ \\
\hline $3 / 4$ & 185 & 35 & 111 & & \\
\hline \multicolumn{6}{|l|}{$\mathrm{pN}, \mathrm{n}$} \\
\hline $0 / 1$ & 532 & 64 & 167 & $0.416^{\mathrm{b}}$ & $0.308^{\mathrm{b}}$ \\
\hline $2 / 3$ & 129 & 25 & 51 & & \\
\hline \multicolumn{6}{|l|}{ pStage, $n$} \\
\hline $\mathrm{I}$ & 419 & 46 & 115 & $0.019^{\mathrm{b}}$ & $0.939^{\mathrm{b}}$ \\
\hline II/III & 242 & 43 & 103 & & \\
\hline \multicolumn{6}{|l|}{ Lymphatic invasion, $\mathrm{n}$} \\
\hline Negative & 368 & 51 & 118 & $0.503^{\mathrm{b}}$ & $0.711^{\mathrm{b}}$ \\
\hline Positive & 293 & 38 & 100 & & \\
\hline \multicolumn{6}{|l|}{ Venous invasion, $\mathrm{n}$} \\
\hline Negative & 546 & 73 & 201 & $0.006^{\mathrm{b}}$ & $0.017^{\mathrm{b}}$ \\
\hline Positive & 115 & 16 & 17 & & \\
\hline \multicolumn{6}{|l|}{ Recurrence, $n$} \\
\hline Peritoneum & 30 & 11 & 38 & $0.001^{\mathrm{c}}$ & $0.177^{\mathrm{c}}$ \\
\hline Liver & 32 & 2 & 2 & $0.006^{\mathrm{c}}$ & $0.330^{c}$ \\
\hline Lymph nodes & 30 & 3 & 9 & $0.519^{c}$ & $0.523^{c}$ \\
\hline Other & 18 & 3 & 7 & $0.449^{c}$ & $0.593^{c}$ \\
\hline
\end{tabular}

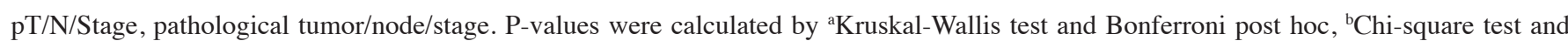
${ }^{c}$ Fisher's exact test.

Of the cases with pathological stage II or III, the proportion of patients who received postoperative adjuvant chemotherapy was $61 \%$ in Sig, $67 \%$ in Por2, and $49 \%$ in intestinal type. Although there was no significant difference among all patients who received adjuvant chemotherapy with $S-1$, the 5 -year survival rate was marginally lower for the diffuse type than for the intestinal type in stage III (Fig. 2A and B). Regarding recurrence-free survival (RFS), there were few survival differences (Fig. 2C and D).

Comparing Por2 and Sig in pathological stage III, the prognosis of patients with Sig was significantly worse than that of patients with intestinal type (Fig. 3A and B). There was little effect on RFS in patients with Por2, but patients with Sig had significantly worse RFS (Fig. 3C and D). In other words, patients with Sig are more likely to experience an early relapse while taking S-1.

\section{Discussion}

In this study, the prognosis of patients with diffuse mixed type gastric cancer was worse than that of patients with intestinal type in pathological stage III. Moreover, in stage III patients who received postoperative adjuvant chemotherapy with S-1, patients with Sig had a significantly 
Table II. Comparison of patient background characteristics between Sig and Por2 groups.

\begin{tabular}{|c|c|c|c|c|c|c|}
\hline Characteristics & $\underset{(n=130)}{\operatorname{Sig}}$ & $\begin{array}{c}\text { Por2 } \\
(\mathrm{n}=118)\end{array}$ & $\begin{array}{c}\text { P-value } \\
\text { (Sig vs. Por2) }\end{array}$ & Sig with Por2 $(n=59)$ & $\begin{array}{c}\text { P-value } \\
\text { (Sig vs. Sig with Por2) }\end{array}$ & $\begin{array}{c}\text { P-value } \\
\text { (Por2 vs. Sig with Por2) }\end{array}$ \\
\hline Mean age $\pm S D$, years & $62 \pm 12$ & $63 \pm 12$ & $0.520^{\mathrm{a}}$ & $64 \pm 13$ & $0.173^{\mathrm{a}}$ & $0.561^{\mathrm{a}}$ \\
\hline \multicolumn{7}{|l|}{ Sex, n } \\
\hline Male & 67 & 77 & $0.169^{\mathrm{b}}$ & 34 & $0.529^{\mathrm{b}}$ & $0.328^{\mathrm{b}}$ \\
\hline Female & 63 & 41 & & 25 & & \\
\hline \multicolumn{7}{|l|}{ Macroscopic type, $\mathrm{n}$} \\
\hline Type 0 & 93 & 43 & $<0.001^{\mathrm{b}}$ & 24 & $<0.001^{\mathrm{b}}$ & $0.574^{\mathrm{b}}$ \\
\hline Type 1-3 & 35 & 61 & & 27 & & \\
\hline Type 4 & 2 & 14 & & 8 & & \\
\hline \multicolumn{7}{|l|}{ pT, n } \\
\hline $1 / 2$ & 108 & 47 & $<0.001^{\mathrm{b}}$ & 26 & $<0.001^{\mathrm{b}}$ & $0.669^{b}$ \\
\hline $3 / 4$ & 22 & 71 & & 33 & & \\
\hline \multicolumn{7}{|l|}{$\mathrm{pN}, \mathrm{n}$} \\
\hline $0 / 1$ & 116 & 77 & $0.002^{\mathrm{b}}$ & 38 & $<0.001^{\mathrm{b}}$ & $0.751^{\mathrm{b}}$ \\
\hline $2 / 3$ & 14 & 41 & & 21 & & \\
\hline \multicolumn{7}{|l|}{ pStage, $\mathrm{n}$} \\
\hline I & 101 & 39 & $<0.001^{\mathrm{b}}$ & 21 & $<0.001^{\mathrm{b}}$ & $0.831^{\mathrm{b}}$ \\
\hline II/III & 29 & 79 & & 38 & & \\
\hline \multicolumn{7}{|l|}{ Lymphatic invasion, $\mathrm{n}$} \\
\hline Negative & 96 & 48 & $<0.001^{\mathrm{b}}$ & 25 & $<0.001^{\mathrm{b}}$ & $0.932^{\mathrm{b}}$ \\
\hline Positive & 34 & 70 & & 34 & & \\
\hline \multicolumn{7}{|l|}{ Venous invasion, $\mathrm{n}$} \\
\hline Negative & 122 & 98 & $0.041^{\mathrm{b}}$ & 54 & $0.749^{b}$ & $0.409^{\mathrm{b}}$ \\
\hline Positive & 8 & 20 & & 5 & & \\
\hline \multicolumn{7}{|l|}{ Recurrence, $\mathrm{n}$} \\
\hline Peritoneum & 12 & 20 & $0.412^{\mathrm{c}}$ & 17 & $0.001^{\mathrm{c}}$ & $0.079^{c}$ \\
\hline Liver & 0 & 3 & $0.160^{\mathrm{c}}$ & 1 & $0.312^{\mathrm{c}}$ & $1.000^{\mathrm{c}}$ \\
\hline Lymph nodes & 3 & 7 & $0.224^{\mathrm{c}}$ & 2 & $0.648^{c}$ & $0.720^{\mathrm{c}}$ \\
\hline other & 2 & 7 & $0.049^{c}$ & 1 & $1.000^{\mathrm{c}}$ & $0.272^{\mathrm{c}}$ \\
\hline
\end{tabular}

Sig, signet ring cell carcinoma; Por2, non-solid poorly differentiated adenocarcinoma; pT/N/Stage, pathological tumor/node/stage. P-values were calculated by ${ }^{a}$ Kruskal-Wallis test and Bonferroni's post hoc test, ${ }^{\mathrm{b}} \mathrm{Chi}$-square test and ${ }^{\mathrm{c}}$ Fisher's exact test.

worse prognosis than patients with non-solid type poorly gastric carcinoma.

The diffuse type was more common in women and younger patients, and it was associated with type 4 cancer and peritoneal metastases as the site of initial recurrence after surgery. A meta-analysis of 73 studies showed that patients with diffuse type had the worst prognosis (8). They found that the risk of death was increased by $23 \%$ regardless of race, stage, and chemotherapy. Microsatellite instability (MSI) of four genomic subtypes classified by the TCGA study of gastric cancer was mainly present in intestinal distal cancer, whereas chromosomal instability was seen in diffuse type cancers (9). In the molecular classification of the Asian Cancer Research Group (ACRG), diffuse type corresponds to microsatellite stable and the epithelial-to-mesenchymal transition (MSS/EMT) phenotype (10). The MSS/EMT was often observed in stage III/IV advanced gastric cancer and had the worst prognosis due to frequent peritoneal metastases. The
EMT was also observed in younger patients and corresponded to Laurén's diffuse type (11). Thus, diffuse gastric cancer cells appear to possess the capacity for epithelial-mesenchymal transition, which promotes peritoneal metastasis (12). Mixed type was seen in $15 \%$ of patients, and they showed a metastatic, as well as a prognostic, pattern similar to predominant Sig and Por2 tumors. Chen et al examined 3071 patients with gastric cancer and divided them into three groups according to the Lauren classification: intestinal type $46 \%$, diffuse type $32 \%$, and mixed type $21 \%$. They demonstrated that the clinical appearance and outcome of mixed type in the Lauren classification were similar to those of diffuse type gastric cancer (5).

In the diffuse type, the two histotypes of Sig and Por2 differ in their clinical and molecular features to the point of representing distinct entities (13). Poorly differentiated carcinoma cells have the potential to convert into the EMT phenotype. On the other hand, Sig is also common in early-stage cancers, and the overall prognostic impact of the presence or absence 
Table III. Impact of histological occupancy in patients with diffuse type.

\begin{tabular}{|c|c|c|c|c|c|c|}
\hline Characteristics & $\begin{array}{l}\text { Sig predominant } \\
\qquad(\mathrm{n}=79)\end{array}$ & $\begin{array}{l}\text { Sig non-predominant } \\
\qquad(\mathrm{n}=110)\end{array}$ & P-value & $\begin{array}{l}\text { Por2 predominant } \\
\qquad(\mathrm{n}=139)\end{array}$ & $\begin{array}{l}\text { Por2 non-predominant } \\
\qquad(\mathrm{n}=38)\end{array}$ & P-value \\
\hline Mean age $\pm S D$, years & $60 \pm 13$ & $64 \pm 12$ & $0.138^{a}$ & $63 \pm 13$ & $66 \pm 11$ & $0.891^{\mathrm{a}}$ \\
\hline \multicolumn{7}{|l|}{ Sex, $\mathrm{n}$} \\
\hline Male & 35 & 66 & \multirow[t]{2}{*}{$0.039^{\mathrm{b}}$} & 86 & 25 & \multirow[t]{2}{*}{$0.709^{\mathrm{b}}$} \\
\hline Female & 44 & 44 & & 53 & 13 & \\
\hline \multicolumn{7}{|l|}{ Macroscopic type, $\mathrm{n}$} \\
\hline Type 0 & 58 & 59 & \multirow[t]{3}{*}{$0.077^{\mathrm{b}}$} & 54 & 13 & \multirow[t]{3}{*}{$0.700^{\mathrm{b}}$} \\
\hline Type 1-3 & 19 & 43 & & 68 & 22 & \\
\hline Type 4 & 2 & 10 & & 17 & 3 & \\
\hline \multicolumn{7}{|l|}{$\mathrm{pT}, \mathrm{n}$} \\
\hline $1 / 2$ & 67 & 67 & \multirow[t]{2}{*}{$0.001^{\mathrm{b}}$} & 60 & 13 & \multirow[t]{2}{*}{$0.091^{\mathrm{b}}$} \\
\hline $3 / 4$ & 12 & 43 & & 79 & 25 & \\
\hline \multicolumn{7}{|l|}{$\mathrm{pN}, \mathrm{n}$} \\
\hline $0 / 1$ & 72 & 82 & \multirow[t]{2}{*}{$0.002^{b}$} & 95 & 20 & \multirow[t]{2}{*}{$0.131^{b}$} \\
\hline $2 / 3$ & 7 & 28 & & 44 & 18 & \\
\hline \multicolumn{7}{|l|}{ pStage, $\mathrm{n}$} \\
\hline $\mathrm{I}$ & 64 & 58 & \multirow[t]{2}{*}{$0.001^{\mathrm{b}}$} & 51 & 9 & \multirow[t]{2}{*}{$0.310^{\mathrm{b}}$} \\
\hline II/III & 15 & 52 & & 88 & 29 & \\
\hline \multicolumn{7}{|l|}{ Lymphatic invasion, $\mathrm{n}$} \\
\hline Negative & 59 & 62 & \multirow[t]{2}{*}{$0.018^{\mathrm{b}}$} & 59 & 14 & \multirow[t]{2}{*}{$0.461^{\mathrm{b}}$} \\
\hline Positive & 20 & 48 & & 80 & 24 & \\
\hline \multicolumn{7}{|l|}{ Venous invasion, $\mathrm{n}$} \\
\hline Negative & 74 & 102 & \multirow[t]{2}{*}{$0.841^{\mathrm{b}}$} & 127 & 25 & \multirow[t]{2}{*}{$0.001^{b}$} \\
\hline Positive & 5 & 8 & & 12 & 13 & \\
\hline \multicolumn{7}{|l|}{ Recurrence, $n$} \\
\hline Peritoneum & 6 & 23 & $0.014^{\mathrm{c}}$ & 32 & 5 & $0.260^{\mathrm{c}}$ \\
\hline Liver & 0 & 1 & $1.000^{\mathrm{c}}$ & 2 & 2 & $0.202^{\mathrm{c}}$ \\
\hline Lymph nodes & 2 & 3 & $1.000^{\mathrm{c}}$ & 7 & 2 & $1.000^{\mathrm{c}}$ \\
\hline Other & 1 & 2 & $1.000^{c}$ & 6 & 2 & $0.681^{\mathrm{c}}$ \\
\hline
\end{tabular}

Sig, signet ring cell carcinoma; Por2, non-solid poorly differentiated adenocarcinoma; pT/N/Stage, pathological tumor/node/stage. P-values were calculated by ${ }^{a}$ Kruskal-Wallis test and Bonferroni's post hoc test, ${ }^{\mathrm{b}} \mathrm{Chi}$-square test and ${ }^{\mathrm{c}}$ Fisher's exact test.

of Sig is equivocal (14-16). Pure Sig is usually present in the intramucosal layer, whereas its morphology is often lost during tumor growth and transformation into poorly cohesive carcinoma (17). Sig can easily transform into poorly cohesive carcinoma in invasive areas and is most frequent in advanced gastric cancer (18). Piessen et al demonstrated that Sig often developed peritoneal metastasis and lymph node invasion and would often fail $\mathrm{R} 0$ resection, and Sig was associated with a worse prognosis than non-Sig in a group matched-controlled study (19). Possible reasons for a poor prognosis are unsuspected peritoneal carcinomatosis and lymph node involvement, which are frequent. We previously reported that Signet ring cells themselves have the capacity to produce immune suppressive enzymes, which increased metastasis (20). Therefore, Sig in advanced gastric cancer is associated with a poorer prognosis than the poorly differentiated type.

The predictive effect of each histological subtype on the efficacy of chemotherapy has not been definitively elucidated.
A decrease in the objective response rate was found in the presence of a diffuse component of advanced gastric cancer. The Laurén diffuse type of gastric cancer is frequently highly infiltrative and resistant to chemotherapy (21). Yoon et al demonstrated that RhoA activity plays a critical role in maintaining cancer stem cell phenotype, and direct RhoA inhibition was effective with chemotherapy (22). The survival rate was better in intestinal type than in diffuse type with regimens containing docetaxel. Subgroup analysis of JCOG9912 indicated that S-1 was more effective than 5-FU alone in the treatment of diffuse type (23). S-1 combined with docetaxel therapy was superior to S-1 monotherapy in patients with diffuse type in the START trial (24). The outcomes in the present study suggest that more intensive adjuvant chemotherapy is required for stage III diffuse type. In addition, in the examination according to histological type, the prognosis was poor in cases in which Sig was histologically mixed. In other words, considering the above-mentioned tendency of Sig to 
Table IV. Risk factors for peritoneal recurrence.

\begin{tabular}{|c|c|c|c|c|}
\hline \multirow[b]{2}{*}{ Characteristics } & \multicolumn{2}{|c|}{ Univariate analysis } & \multicolumn{2}{|c|}{ Multivariate analysis } \\
\hline & HR $(95 \%$ CI $)$ & P-value & HR $(95 \% \mathrm{CI})$ & P-value \\
\hline Age & $0.61(0.07-4.27)$ & 0.6312 & & \\
\hline \multicolumn{5}{|l|}{ Macroscopic type } \\
\hline Type 4 vs. type 0 & $5.60(1.24-30.78)$ & 0.025 & $2.19(0.23-50.1)$ & 0.710 \\
\hline \multicolumn{5}{|l|}{ Surgery } \\
\hline Total gastrectomy vs. distal gastrectomy & $4.18(1.95-9.60)$ & 0.0002 & $3.70(1.59-9.16)$ & 0.002 \\
\hline \multicolumn{5}{|l|}{ Histology } \\
\hline Por2 vs. non-Por2 & $3.27(1.58-6.92)$ & 0.0015 & $2.23(0.90-5.58)$ & 0.081 \\
\hline Sig vs. non-Sig & $4.23(1.92-9.26)$ & 0.0004 & $3.34(1.37-8.16)$ & 0.009 \\
\hline \multicolumn{5}{|l|}{ pT category } \\
\hline pT4a vs. pT3 & $2.39(1.10-5.57)$ & 0.0272 & $1.61(0.63-4.27)$ & 0.135 \\
\hline \multicolumn{5}{|l|}{ pN category } \\
\hline pN3 vs. pN1 & $2.65(0.92-8.82)$ & 0.0713 & & \\
\hline \multicolumn{5}{|l|}{ Lymphatic invasion } \\
\hline Positive vs. negative & $1.38(0.47-4.60)$ & 0.569 & & \\
\hline \multicolumn{5}{|l|}{ Venous invasion } \\
\hline Positive vs. negative & $0.39(0.06-2.85)$ & 0.728 & & \\
\hline
\end{tabular}

HR, hazard ratio; Sig, signet ring cell carcinoma; Por2, non-solid poorly differentiated adenocarcinoma; pT/N, pathological tumor/node.

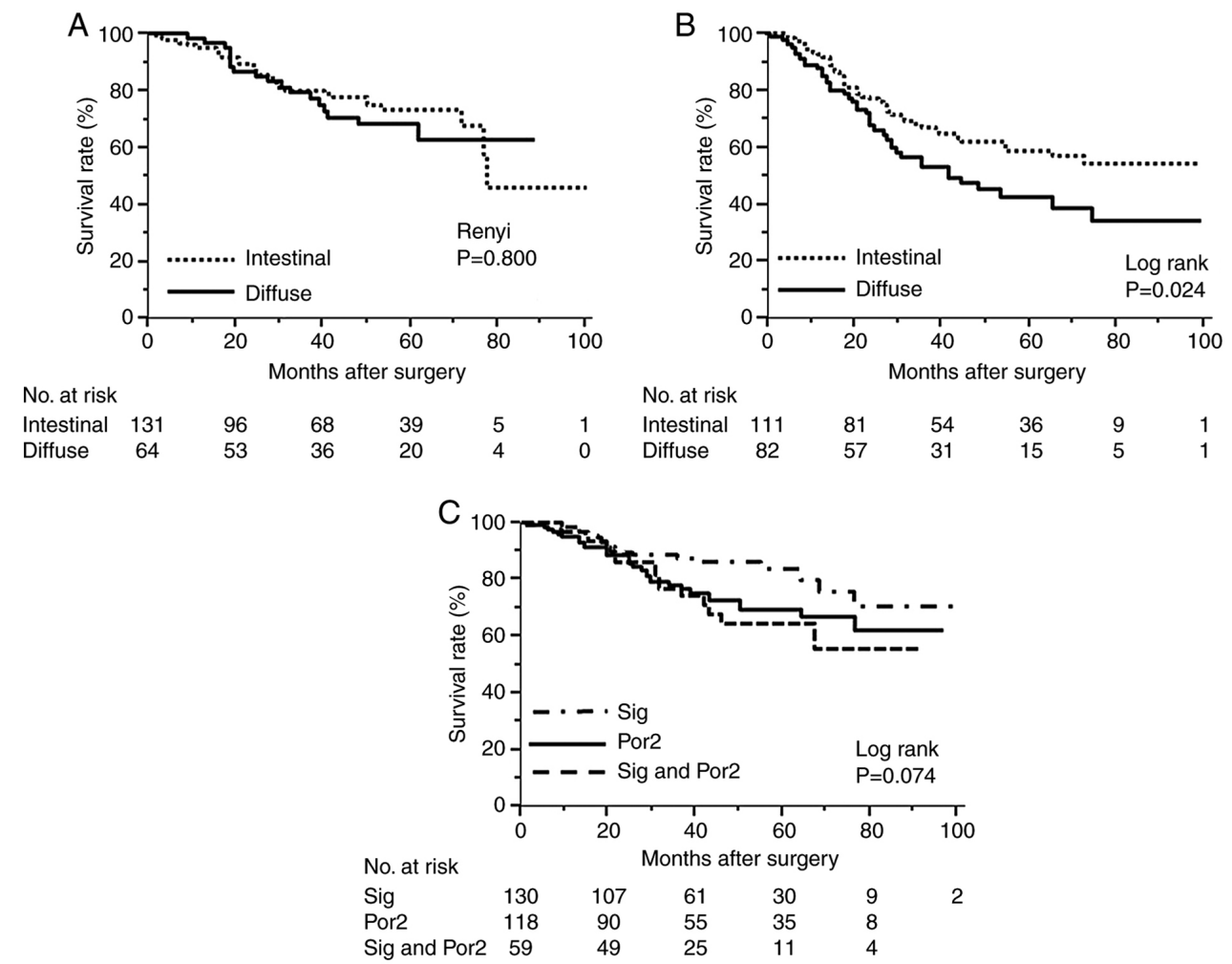

Figure 1. Kaplan-Meier curves comparing overall survival in diffuse type and intestinal type are shown for (A) pathological stage II and (B) stage III. (C) Survival curves of the histological difference between Sig and Por2. No. at risk indicates the number of patients excluding those who died or were lost to follow-up at each time after surgery. Sig, signet ring cell carcinoma; Por2, non-solid poorly differentiated adenocarcinoma.

cause peritoneal dissemination, it appears that stronger adjuvant chemotherapy is necessary for cases with Sig in Stage III.
It has recently been reported that $\mathrm{S}-1$ plus docetaxel improved efficacy in patients with stage III gastric cancer (7). If effective 

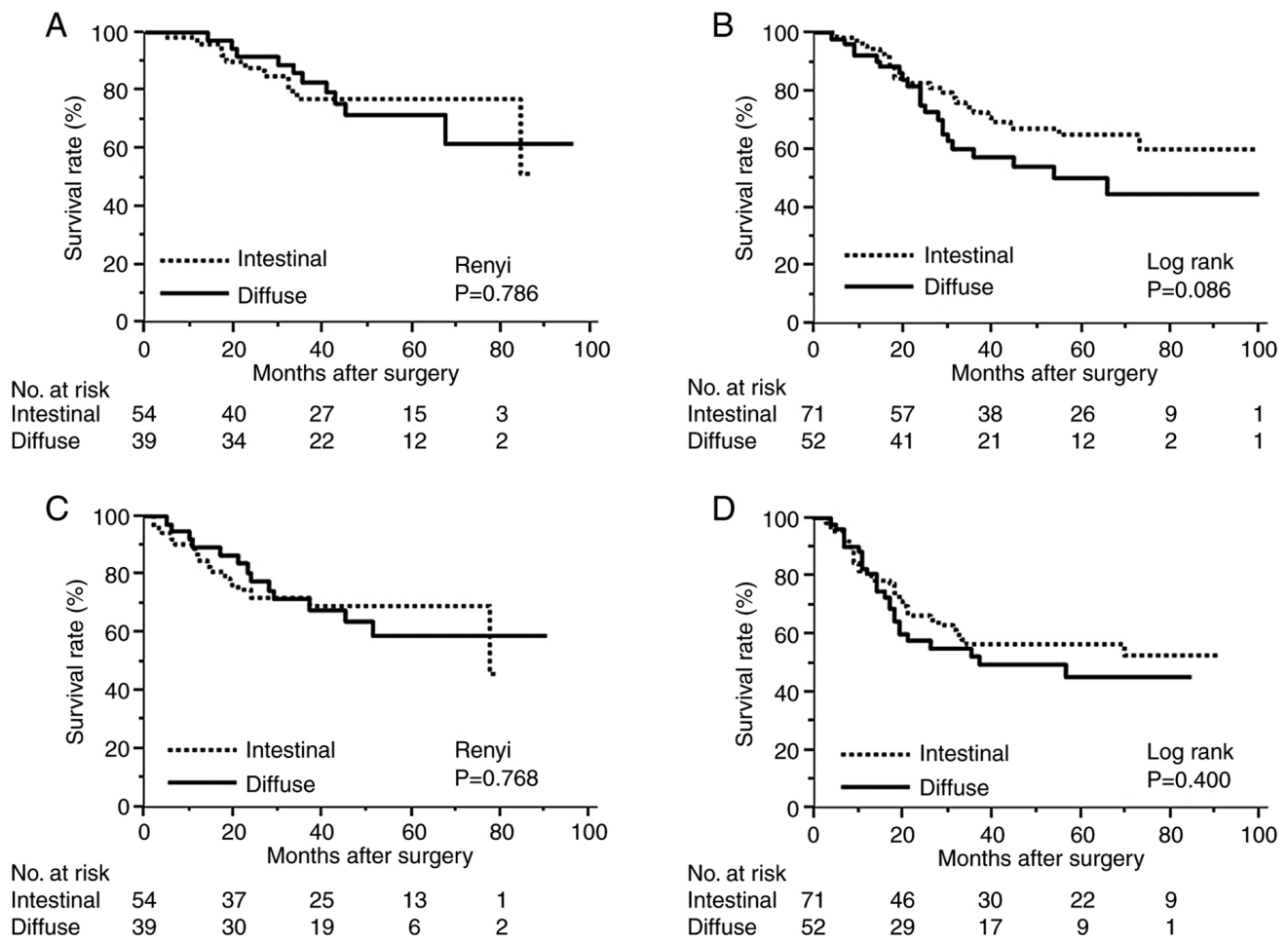

Figure 2. Kaplan-Meier curves comparing overall survival in patients with (A) pathological stage II and (B) stage III gastric cancer, and relapse-free survival in patients with (C) pathological stage II and (D) stage III gastric cancer, between diffuse type and intestinal type treated with S-1 adjuvant chemotherapy. No. at risk indicates the number of patients excluding those who died or were lost to follow-up at each time after surgery.
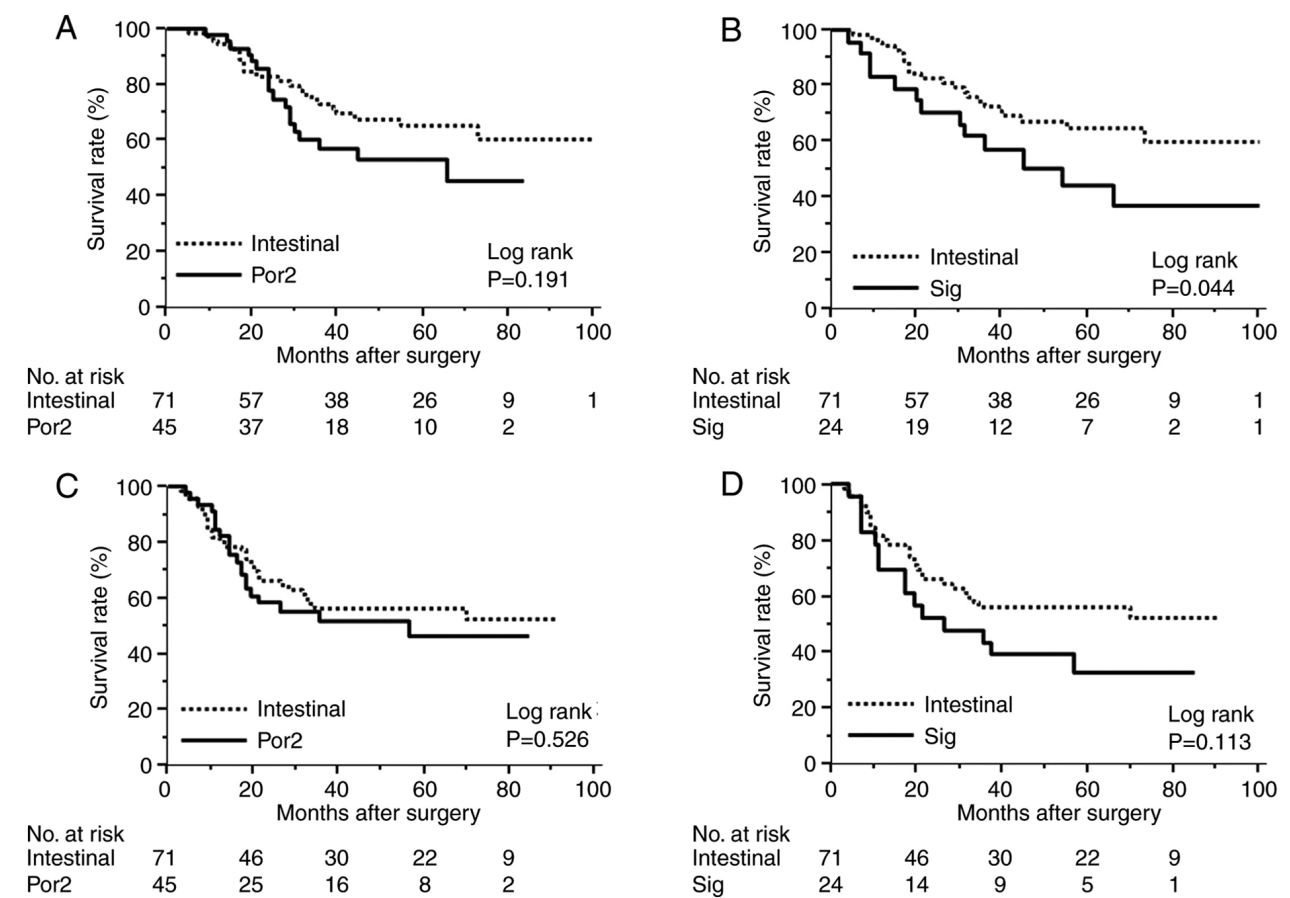

Figure 3. Kaplan-Meier curves comparing overall survival between intestinal type and (A) Por2 and (B) Sig, and relapse-free survival between intestinal type and (C) Por2 and (D) Sig, in patients with stage III gastric cancer treated with S-1 adjuvant chemotherapy. No. at risk indicates the number of patients excluding those who died or were lost to follow-up at each time after surgery. Sig, signet ring cell carcinoma; Por2, non-solid poorly differentiated adenocarcinoma.

intraperitoneal treatment is developed, it should be directed at patients with a high risk of peritoneal recurrence. More effective adjuvant therapy is needed, perhaps with immunotherapy or new target agents.
The limitations of this study are that it was a retrospective study in a single institution. However, the subjects of this study were accumulated over a period of approximately 12 years, indicating an adequate investigation. Furthermore, the impact 
of histology on second-line chemotherapy, which could affect OS, was not examined.

In conclusion, Sig, when observed in advanced cancer tissue, is associated with a high rate of peritoneal recurrence even after radical resection. The present results suggest that early recurrence during postoperative adjuvant chemotherapy should be considered in patients with stage III gastric cancer showing histological coexistence of Sig.

\section{Acknowledgements}

Not applicable.

\section{Funding}

No funding was received.

\section{Availability of data and materials}

The datasets used and/or analyzed in the current study are available from the corresponding author on reasonable request.

\section{Authors' contributions}

HT acquired, analyzed and interpreted the data, confirmed the authenticity of the data and drafted the manuscript. MY made substantial contributions to the conception and design of the study, interpreted the data, confirmed the authenticity of the data and revised the manuscript critically. TI reviewed and oversaw the data on the statistics section of the Renyi test. TTa, TTo and KM acquired and analyzed the data. KH and MO contributed to the conception and design of the study, and critically revised the manuscript. All authors read and approved the final manuscript.

\section{Ethics approval and consent to participate}

This investigation was carried out according to the Declaration of Helsinki. All experimental procedures after 2013 were approved by the Osaka City University ethics committee (approval no. 4423), and all patients provided written informed consent for collection and analysis of the specimens. On the other hand, because the other experimental procedures up to 2013 were performed with only all-inclusive consent, it was considered an observational study with an opt-out form.

\section{Patient consent for publication}

Not applicable.

\section{Competing interests}

The authors declare that they have no competing interests.

\section{References}

1. Lauren P: The two histological main types of gastric carcinoma: Diffuse and so-called intestinal-type carcinoma. An attempt at a histo-clinical classification. Acta Pathol Microbiol Scand 64: 31-49, 1965.
2. Japanese Gastric Cancer Association: Japanese classification of gastric carcinoma: 3rd English edition. Gastric Cancer 14: 101-112, 2011.

3. Nagtegaal ID, Odze RD, Klimstra D, Paradis V, Rugge M, Schirmacher P, Washington KM, Carneiro F, Cree IA; WHO Classification of Tumours Editorial Board: The 2019 WHO classification of tumours of the digestive system. Histopathology 76 : 182-188, 2020.

4. Lee JH, Chang KK, Yoon C, Tang LH, Strong VE and Yoon SS: Lauren histologic type is the most important factor associated with pattern of recurrence following resection of gastric adenocarcinoma. Ann Surg 267: 105-113, 2018.

5. Chen YC, Fang WL, Wang RF, Liu CA, Yang MH, Lo SS, Wu CW, Li AFY, Shyr YM and Huang KH: Clinicopathological variation of lauren classification in gastric cancer. Pathol Oncol Res 22: 197-202, 2016.

6. Sasako M, Sakuramoto S, Katai H, Kinoshita T, Furukawa H, Yamaguchi T, Nashimoto A, Fujii M, Nakajima T and Ohashi Y: Five-year outcomes of a randomized phase III trial comparing adjuvant chemotherapy with $\mathrm{S}-1$ versus surgery alone in stage II or III gastric cancer. J Clin Oncol 29: 4387-4393, 2011.

7. Yoshida K, Kodera Y, Kochi M, Ichikawa W, Kakeji Y, Sano T, Nagao N, Takahashi M, Takagane A, Watanabe T, et al: Addition of docetaxel to oral fluoropyrimidine improves efficacy in patients with stage III gastric cancer: Interim analysis of JACCRO GC-07, a randomized controlled trial. J Clin Oncol 37: 1296-1304, 2019.

8. Petrelli F, Berenato R, Turati L, Mennitto A, Steccanella F, Caporale M, Dallera P, de Braud F, Pezzica E, Di Bartolomeo $\mathrm{M}$, et al: Prognostic value of diffuse versus intestinal histotype in patients with gastric cancer: A systematic review and meta-analysis. J Gastrointest Oncol 8: 148-163, 2017.

9. Cancer Genome Atlas Research Network: Comprehensive molecular characterization of gastric adenocarcinoma. Nature 513: 202-209, 2014.

10. Cristescu R, Lee J, Nebozhyn M, Kim KM, Ting JC, Wong SS, Liu J, Yue YG, Wang J, Yu K, et al: Molecular analysis of gastric cancer identifies subtypes associated with distinct clinical outcomes. Nat Med 21: 449-456, 2015.

11. Cislo M, Filip AA, Arnold Offerhaus GJ, Ciseł B, Rawicz-Pruszyński K, Skierucha M and Polkowski WP: Distinct molecular subtypes of gastric cancer: From Lauren to molecular pathology. Oncotarget 9: 19427-19442, 2018.

12. Zheng HC, Li XH, Hara T, Masuda S, Yang XH, Guan YF and Takano Y: Mixed-type gastric carcinomas exhibit more aggressive features and indicate the histogenesis of carcinomas. Virchows Arch 452: 525-534, 2008.

13. Fujimoto A, Ishikawa Y, Ishii T, Yamada A, Igarashi Y, Ohmoto Y and Kaise M: Differences between gastric signet-ring cell carcinoma and poorly differentiated adenocarcinoma: A comparison of histopathologic features determined by mucin core protein and trefoil factor family peptide immunohistochemistry. Pathol Int 67: 398-403, 2017.

14. Pernot S, Voron T, Perkins G, Lagorce-Pages C, Berger A and Taieb J: Signet-ring cell carcinoma of the stomach: Impact on prognosis and specific therapeutic challenge. World J Gastroenterol 21: 11428-11438, 2015.

15. Li C, Kim S, Lai JF, Hyung WJ, Choi WH, Choi SH and Noh SH: Advanced gastric carcinoma with signet ring cell histology. Oncology 72: 64-68, 2007.

16. Chon HJ, Hyung WJ, Kim C, Park S, Kim JH, Park CH, Ahn JB, Kim H, Chung HC, Rha SY, et al: Differential prognostic implications of gastric signet ring cell carcinoma: stage adjusted analysis from a single high-volume center in Asia. Ann Surg 265: 946-953, 2017.

17. Lee SH, Jee SR, Kim JH and Seol SY: Intramucosal gastric cancer: The rate of lymph node metastasis in signet ring cell carcinoma is as low as that in well-differentiated adenocarcinoma. Eur J Gastroenterol Hepatol 27: 170-174, 2015.

18. Machlowska J, Puculek M, Sitarz M, Terlecki P, Maciejewski R and Sitarz R: State of the art for gastric signet ring cell carcinoma: From classification, prognosis, and genomic characteristics to specified treatments. Cancer Manag Res 11: 2151-2161, 2019.

19. Piessen G, Messager M, Leteurtre E, Jean-Pierre T and Mariette C: Signet ring cell histology is an independent predictor of poor prognosis in gastric adenocarcinoma regardless of tumoral clinical presentation. Ann Surg 250: 878-887, 2009.

20. Yoshii M, Tanaka H, Ohira M, Muguruma K, Iwauchi T, Lee T, Sakurai K, Kubo N, Yashiro M, Sawada T and Hirakawa K: Expression of Forkhead box P3 in tumour cells causes immunoregulatory function of signet ring cell carcinoma of the stomach. Br J Cancer 106: 1668-1674, 2012. 
21. Jimenez Fonseca P, Carmona-Bayonas A, Hernandez R, Custodio A, Cano JM, Lacalle A, Echavarria I, Macias I, Mangas M, Visa L, et al: Lauren subtypes of advanced gastric cancer influence survival and response to chemotherapy: Real-world data from the AGAMENON national cancer registry. Br J Cancer 117: 775-782, 2017.

22. Yoon C, Cho SJ, Aksoy BA, Park DJ, Schultz N, Ryeom SW and Yoon SS: Chemotherapy resistance in diffuse-type gastric adenocarcinoma is mediated by RhoA activation in cancer stem-like cells. Clin Cancer Res 22: 971-983, 2016.

23. Takahari D, Boku N, Mizusawa J, Takashima A, Yamada Y, Yoshino T, Yamazaki K, Koizumi W, Fukase K, Yamaguchi K, et al: Determination of prognostic factors in Japanese patients with advanced gastric cancer using the data from a randomized controlled trial, Japan clinical oncology group 9912. Oncologist 19: 358-366, 2014.
24. Koizumi W, Kim YH, Fujii M, Kim HK, Imamura H, Lee KH, Hara T, Chung HC, Satoh T, Cho JY, et al: Addition of docetaxel to S-1 without platinum prolongs survival of patients with advanced gastric cancer: A randomized study (START). J Cancer Res Clin Oncol 140: 319-328, 2014

This work is licensed under a Creative Commons Attribution-NonCommercial-NoDerivatives 4.0 International (CC BY-NC-ND 4.0) License. 